\title{
ANALISA LAJU KOROSI PLAT A36 UNTUK DECK FLOATIN G DOCK VENTURE 3 DENGAN PERLINDUNGAN ZINC ANODE DAN ARUS DC SERTA ZINC ANODE TANPA MENGGUNAKAN ARUS DC
}

\author{
Sri Endah Susilowati ${ }^{2}$, Jadi Martua Simbolon*1 \\ Universitas 17 Agustus 1945 Jakarta \\ Jalan Sunter Permai Raya No.36, Sunter Agung, Tj. Priok, Kota Jkt Utara, DKI Jakarta, 14350 \\ Email: sriendah.susilowati@yahoo.com
}

\begin{abstract}
Abstrak
Korosi atau perkaratan sangat lazim terjadi pada besi. Besi merupakan logam yang mudah berkarat. Karat besi merupakan zat yang dihasilkan pada peristiwa korosi, yaitu berupa zat padat berwarna coklat kemerahan yang bersifat rapuh serta berpori. Rumus kimia dari karat besi adalah $\mathrm{Fe}_{2} \mathrm{O}_{3} \times \mathrm{H}_{2} \mathrm{O}$. Bila dibiarkan, lama kelamaan besi akan habis menjadi karat. Dampak dari peristiwa korosi bersifat sangat merugikan. Peristiwa korosi sendiri merupakan proses elektrokimia, yaitu reaksi kimia yang melibatkan adanya aliran listrik. Bagian tertentu dari besi berlaku sebagai kutub negatif (elektroda negatif, anoda), sementara bagian yang lain sebagai kutub positif (elektroda positif, katoda). Elektron mengalir dari anoda ke katoda, sehingga terjadilah peristiwa korosi. Penelitian laju korosi ini menggunakan plat A36 untuk Deck Floating Dock Venture dengan tiga macam perlakuan, yaitu Plat tanpa perlindungan korosi (A), dengan perlindungan zinc anode (B) serta perlindungan gabungan dari zinc anode dan arus listrik $D C(C)$. Laju korosi dihitung dengan menggunakan metode kehilangan berat. Hasil penelitian menunjukkan besarnya laju korosi pada perlakuan A, B dan $C$ berturut-turut adalah : 0,66 mpy, 0,22 mpy dan 0,17 mpy. Perlakuan dengan menggunakan perlindungan zinc anode dan arus DC menghasilkan nilai laju kekerasan paling kecil diantara yang lain. Untuk nilai kekerasan yang diuji menggunakan Brinnnel Number Test nilainya berturut-turut adalah : 136,3 BHN, 205,2 BHN dan 202,9 BHN. Nilai kekerasan tertinggi pada Plat dengan perlakuan perlindungan zinc anode.
\end{abstract}

Kata kunci :Laju Korosi, Zinc Anode, Arus listrik DC, Floating Dock, Plat A36

\begin{abstract}
Abstrack
Corrosion or rusting is very common in iron. Iron is a metal that is easily corroded. Iron rust is a substance produced in the event of corrosion, which is a reddish brown solid which is fragile and porous. The chemical formula of iron rust is Fe2O3 x H2O. If left unchecked, over time the iron will run out to rust. The impact of corrosion is very detrimental. Corrosion event itself is an electrochemical process, which is a chemical reaction involving an electric current. Certain parts of the iron act as negative poles (negative electrodes, anodes), while other parts are positive poles (positive electrodes, cathodes). Electrons flow from the anode to the cathode, resulting in a corrosion event. This corrosion rate research uses A36 plate for Deck Floating Dock Venture with three types of treatment, namely Plate without corrosion protection (A), with zinc anode protection $(B)$ as well as combined protection from zinc anode and DC electric current $(C)$. Corrosion rate is calculated using the weight loss method. The results showed the magnitude of the corrosion rate in treatments $A, B$ and $C$ were: 0.66 mpy, 0.22 mpy and 0.17 mpy. The treatment using zinc anode protection and DC current yields the smallest rate of hardness among others. For the hardness values tested using the Brinnnel Number Test, the values are: 136.3 BHN, 205.2 BHN and 202.9 BHN. The highest hardness value on the Plate with zinc anode protection treatment.
\end{abstract}

Keywords: Corrosion Rate, Zinc Anode, DC Electric Current, Floating Dock, Plate A36

\section{PENDAHULUAN}

Penggunaan plat baja pada deck floating dock kapal merupakan hal umum yang digunakan sebagai bahan pembuatan kapal karena cukup memadai. Tetapi besi dan baja sangat reaktif sehingga mempunyai kecenderungan mengalami korosi di daerah korosif yakni air laut. Korosi merupakan gejala alamiah yang biasa terjadi didalam plat kapal sebagai akibat interaksi dengan lingkungan sekitarnya sehingga mengalami perubahan massa dalam lingkungan korosif. Penelitian ini menguji tentang laju korosi pada plat deck floating dock kapal dengan Zinc Anode dan arus listrik DC. Penentuan proteksi yang tepat pada plat deck floating dock kapal diuji dengan menggunakan metode percobaan larutan air laut dan Zinc Anode dengan arus listrik. Penambahan arus listrik DC pada Zinc Anode akan meningkatkan 
proteksi yang lebih tinggi pada plat baja sehingga resiko kerusakan lebih rendah dan dapat digunakan lebih lama.

Korosi kapal baja mengakibatkan turunnya kekuatan dan umur pakai kapal, sehingga dapat mengurangi jaminan keselamatan muatan barang dan penumpang kapal . Untuk menghindari kerugian yang lebih besar akibat korosi air laut maka diperlukan suatu perlindungan korosi pada plat kapal. Korosi kapal dapat ditanggulangi dengan berbagai cara antara lain dengan menggunakan anoda karbon kapal dan cat kapal.

Wilayah Indonesia yang sebagian besar berupa lautan memiliki banyak sekali struktur atau konstruksi dari bahan logam terutama baja karbon. Konstruksi tersebut selalu berhubungan dengan air laut yang merupakan elektrolit yang korosif. Hal ini mengandung konsekuensi terjadinya serangan korosi terhadap struktur-struktur tersebut, yang dapat menimbulkan kerugian yang besar baik dari segi teknis maupun ekonomis. Berbagai metode pencegahan korosi di lingkungan air laut terus dikembangkan. Salah satunya adalah pemakaian anoda korban yang bekerja berdasarkan prinsip proteksi katodik. Permukaan struktur logam di air laut diubah menjadi bersifat katodik melalui pemberian arus yang berasal dari anoda korban tersebut. Jenis anoda korban yang sesuai dipakai dilingkungan air laut adalah anoda korban paduan seng dan paduan aluminium Tersedianya dua jenis paduan ini memberikan pilihan bagi para pemakai untuk menentukan jenis paduan yang sesuai dengan kebutuhannya. Sasaran utama penelitian ini adalah karena dampak ancaman korosi yang sangat merugikan maka perlu dikembangkan beberapa cara untuk melindungi baja dari segala kerusakan yang mungkin terjadi dengan tujuan memperpanjang umur pakai kapal. Kerusakan karena serangan korosi (karat) merupakan permasalahan umum yang menyebabkan degradasi material sebagai interaksi dengan lingkungannya; sehingga tidak hanya memperburuk penampilannya namun juga memperpendek usia pakai dari baja tersebut. Untuk mencegah serangan berbagai jenis korosi tersebut diperlukan langkah-langkah pencegahan yang cukup mahal biayanya. Namun jika dibandingkan dengan kerugian akibat serangan korosi , maka biaya pencegahan tersebut menjadi hampir tidak berarti. Ada beberapa prinsip pencegahan korosi yang telah berkembang yang umumnya disesuaikan dengan jenis peralatan, tempat, maupun jenis lingkungan yang korosif. Pencegahan korosi pada baja yang cukup luas dikenal adalah dengan cara melapisi baja dengan lapisan penghalang (coatings), dengan perlindungan katoda menggunakan zinc anode dan cara lainnya.

Pengendalian korosi atau proteksi korosi atau yang lebih umum pencegahan korosi terhadap logam dapat dilakukan dengan mengubah potensial antar muka logam dengan lingkungannya. Secara elektrokimia proteksi korosi dapat dikelompokkan menjadi proteksi katodik dan anodik. Pengendalian korosi metoda proteksi katodik dapat dilakukan dengan merubah potensial antar muka logam dengan ionnya ke daerah immun dengan memberikan arus katodik. Penurunan potensial antar muka ke arah immun atau ke daerah lebih katodik dapat dilakukan dengan menghubungkan benda kerja dengan anoda korban.

Zinc anode adalah logam zinc dalam bentuk batangan atau bentuk lain, ditempelkan ke bagian-bagian kapal yang rawan terhadap korosi air laut. Kapal-kapal modern yang mengutamakan kekuatan fisik, daya angkut beban besar, dan kecepatan tinggi, menggunakan baja di sebagian besar konstruksi fisik dan permesinannya. Kapal-kapal besar terdiri dari kapal-kapal niaga, kapal-kapal penumpang, kapalkapal riset dan SAR, serta kapal-kapal perang, dan kapal-kapal untuk kegunaan lainnya. Besi yang merupakan bagian terbesar dari konstruksi kapal, mudah mengalami korosi yang disebabkan oleh air laut.Untuk menurunkan laju korosi yang tinggi, maka baja harus mendapat perlindungan yang baik. Perlindungan didapat melalui pelapisan permukaan baja menggunakan cat anti korosi, dan 
perlindungan bagian-bagian yang penting menggunakan logam-logam yang lebih reaktif sebagai anoda. Proteksi katoda adalah cara pengendalian korosi suatu logam menggunakan reaksi elektrokimia, di mana reaksi oksidasi dalam sel galvanik terkonsentrasi pada anoda, yang mampu menekan laju korosi katoda dalam sel yang sama.

Penelitian ini bertujuan untuk menganalisa laju korosi dengan cara menghitung kehilangan berat serta menguji kekerasan pada plat A36 untuk deck floating dock venture 3 dengan perlindungan zinc anode dan arus DC serta zinc anode tanpa menggunakan arus DC.

\section{METODE PENELITIAN}

Penelitian ini menggunakan metode eksperimen, penelitian dilakukan dengan waktu kurang lebih satu bulan (tiga puluh hari). Plat yang di uji yaitu plat A36 untuk deck floating dock Venture 3 di Galangan Kapal Dock Kodja Bahari III.

\subsection{Peralalatan Yang Digunakan}

- Gelas ukur plastik, charger kabel USB 5V 1A, Plat A36, Zinc Anode, Air Laut, Timbangan Elektrik, Mesin Gurinda, Cutting Wheel, Marker (spidol), Sigmat, Meteran, Blender (lampu potong), Kapur Besi (Baja), Mata Gurinda 4.0 Inchi, Tabung Gas Elpiji dan Tabung Oksigen.

- Alat uji kekerasan (Equotip $\left.{ }^{3}\right)$

\subsection{Material Yang Digunakan}

- Plat A36 dengan diameter $4 \mathrm{~cm}$ x $3 \mathrm{~cm}$ x $1 \mathrm{~cm}$ sebanyak 9 buah

- Zinc anode dengan ukuran $4.8 \mathrm{~cm}$ x $2.9 \mathrm{~cm}$ x $1.7 \mathrm{~cm}$ sebanyak 6 buah

\subsection{Metode Pengambilan Data}

Metode pengumpulan data yang digunakan adalah metode pengumpulan dan pencatatan data hasil pengujian di lapangan selama 30 hari. Hasil yang diperoleh di dihitung dan dianalisi menggunakan rumus kehilangan berat untuk laju korosi.

\subsection{Pelaksanaan Pengujian Laju Korosi}

Langkah-langkah yang dilakukan dalam eksperimen ini adalah sebagai berikut :

1. Menyiapkan alat, perlengkapan yang akan digunakan untuk membuat percobaan uji laju korosi, mulai dari mempersiapkan gelas ukur plastik,air laut, plat, kabel Port USB, dan Zinc Anode

3. Setelah semua siap, percobaan pertama yaitu percobaan laju korosi hanya dengan Plat dan Air laut dimasukkan ke dalam gelas ukur lalu dihitung laju korosi nya setiap 168 jam (7 hari), 336 jam (14 hari), 504 jam (21 hari), hingga 720 jam (30 hari).

4. Pecobaan kedua yaitu dengan metode plat dilindungi dengan Zinc Anode, hasil dari penelitian ditulis mulai dari 168 jam (7 hari), 336 jam (14 hari), 504 jam (21 hari), hingga 720 jam (30 hari).

5. Pecobaan ketiga yaitu plat dilindungi dengan Arus Listrik $D C$ dan Zinc Anode, hasil dari penelitian ditulis setiap 168 jam (7 hari), 336 jam (14 hari), 504 jam (21 hari), hingga 720 jam (30 hari).

6. Setelah 720 jam (30 hari) untuk percobaan laju korosi maka hasilnya dihitung dengan menggunakan rumus laju korosi dengan metode kehilangan berat.

Kondisi aktual yang terjadi pada percobaan plat A36 dengan semua metode yang digunakan seperti pada gambar di bawah ini. 

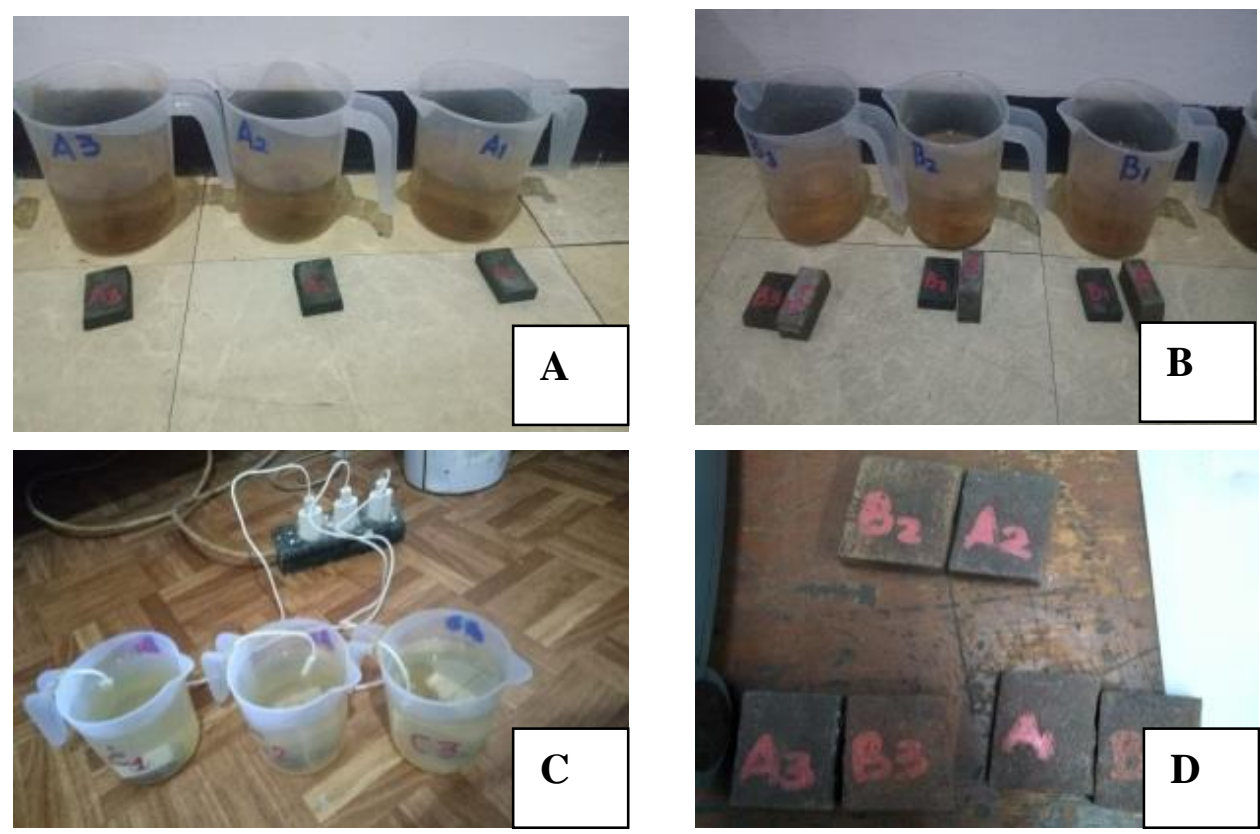

Gambar 1. Material Plat A36 dengan perlakuan : A Tanpa Perlindungan Korosi , B. Dengan Perlindungan Zinc Anode, C . Dengan Perlindungan Zinc Anode Dan Arus DC, D Hasil Percobaan Plat A36

\section{HASIL DAN PEMBAHASAN}

\subsection{Hasil Perhitungan}

Hasil pengamatan di lapangan untuk perlakuan A ( plat tanpa perlindungan), perlakuan B ( plat dengan perlindungan Zinc Anode) dan perlakuan C (( plat dengan perlindungan Zinc Anode dan dialiri arus DC) dirangkum dalam tabel 1 di bawah ini :

Tabel 1. Percobaan Laju Korosi dengan perlakuan A, B dan C (masing-masing 3 kali ulangan) :

\begin{tabular}{ccccccc}
\hline Plat & $\begin{array}{c}\text { Berat awal } \\
\mathbf{( g r})\end{array}$ & $\begin{array}{c}\text { Berat minggu } \\
\mathbf{I}(\mathbf{g r})\end{array}$ & $\begin{array}{c}\text { Berat minggu } \\
\mathbf{I I}(\mathbf{g r})\end{array}$ & $\begin{array}{c}\text { Berat minggu } \\
\text { ke III (gr) }\end{array}$ & $\begin{array}{c}\text { Berat minggu } \\
\text { ke IV (gr) }\end{array}$ & $\begin{array}{c}\text { Berat yang } \\
\text { hilang (gr) }\end{array}$ \\
\hline $\mathrm{A}_{1}$ & 95,00 & 94,50 & 94,10 & 93,70 & 92,80 & 2,20 \\
$\mathrm{~A}_{2}$ & 92,00 & 91,50 & 91,50 & 91,00 & 91,00 & 1,00 \\
$\mathrm{~A}_{3}$ & 93,00 & 92,70 & 92.00 & 91,70 & 91,30 & 1,70 \\
$\mathrm{~B}_{1}$ & 93,00 & 93,00 & 92,90 & 92,70 & 92,60 & 0,40 \\
$\mathrm{~B}_{2}$ & 102,00 & 102,00 & 101,70 & 101,00 & 101,00 & 1,00 \\
$\mathrm{~B}_{3}$ & 99,00 & 99,00 & 98,90 & 98,80 & 98,80 & 0,20 \\
$\mathrm{C}_{1}$ & 78,40 & 78,40 & 78,40 & 78,40 & 78,40 & 0,00 \\
$\mathrm{C}_{2}$ & 79.40 & 79,30 & 79,30 & 79,30 & 79,30 & 0,10 \\
$\mathrm{C}_{3}$ & 76,00 & 76,00 & 76,00 & 76,00 & 76,00 & 0,00 \\
\hline
\end{tabular}

Pengujian laju korosi merupakan pengujian yang dilakukan dengan menggunakan metode perhitungan dari kehilangan berat yang dialami oleh plat. Untuk menghitung Laju Korosi dengan menggunakan rumus di bawah ini : :

$$
\mathbf{C R}=\frac{\mathrm{K} \times \mathbf{W}}{\mathrm{D} \times \mathbf{A} \times \mathbf{T}}
$$

Dimana : 
CR: Laju Korosi (mpy)

W : massa yang terkorosi (gram)

D : densitas $\left(\frac{\mathrm{g}}{\mathrm{cm}^{3}}\right)$ untuk baja $\left(7,87 \frac{\mathrm{g}}{\mathrm{cm}^{3}}\right)$

A : luas plat $\left(\mathrm{cm}^{2}\right)$

$\mathrm{T}$ : waktu (jam)

K : Konstanta $8.76 \times 10^{4}$

Hasil perhitungan laju korosi dengan variasi waktu dan perlakuan disajikan pada tabel 2. dan Gambar 2 di bawah ini :

Tabel 2. Perhitungan Laju Korosi plat A36

\begin{tabular}{cccccc}
\hline Plat & $\begin{array}{c}\text { Berat awal } \\
(\text { gr })\end{array}$ & $\begin{array}{c}\text { Berat minggu } \\
\text { ke IV (gr) }\end{array}$ & $\begin{array}{c}\text { Berat yang } \\
\text { hilang }(\text { gr) }\end{array}$ & $\begin{array}{c}\text { Laju korosi } \\
(\mathbf{m p y})\end{array}$ & $\begin{array}{c}\text { Rata2 laju korosi } \\
(\mathbf{m p y})\end{array}$ \\
\hline $\mathrm{A}_{1}$ & 95,00 & 92,80 & 2,20 & 0,89 & \\
$\mathrm{~A}_{2}$ & 92,00 & 91,00 & 1,00 & 0,41 & 0,66 \\
$\mathrm{~A}_{3}$ & 93,00 & 91,30 & 1,70 & 0,69 & \\
$\mathrm{~B}_{1}$ & 93,00 & 92,60 & 0,40 & 0,16 & \\
$\mathrm{~B}_{2}$ & 102,00 & 101,00 & 1,00 & 0,41 & 0,22 \\
$\mathrm{~B}_{3}$ & 99,00 & 98,80 & 0,20 & 0,08 & \\
$\mathrm{C}_{1}$ & 78,40 & 78,40 & 0,00 & 0,00 & 0,17 \\
$\mathrm{C} 2$ & 79.40 & 79,30 & 0,10 & 0,05 & \\
$\mathrm{C} 3$ & 76,00 & 76,00 & 0,00 & 0,00 & \\
\hline
\end{tabular}

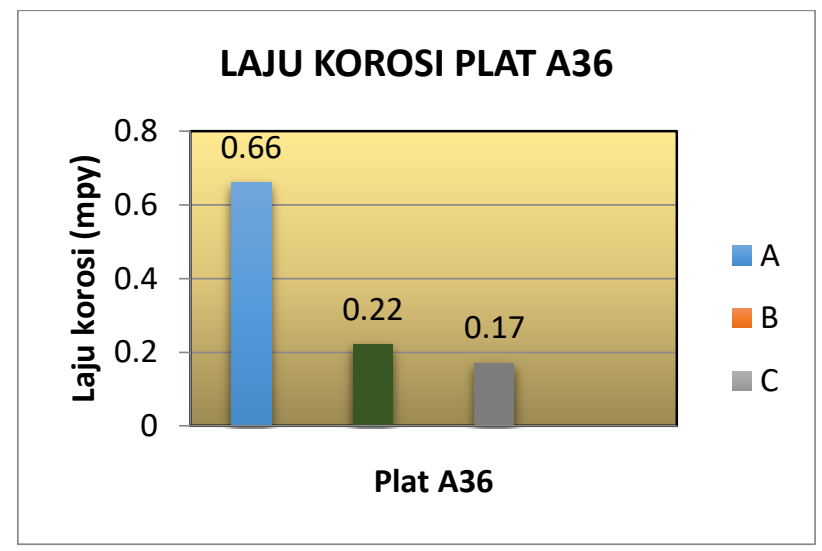

Gambar 2. Laju Korosi pada Berbagai Perlakuan

3.2 Perhitungan Uji Kekerasan Pada Daerah Plat dihitung dengan Brinnel Hardness Number :

$\mathrm{BHN}=\frac{2 P}{\pi D\left(D-\sqrt{\mathrm{D}^{2}}-d^{2}\right.}$

Dimana :

BHN = Brinell Hardness Number

$\mathrm{P}=$ Beban yang diberikan $(\mathrm{kgf})$

$\mathrm{D}=$ Diameter indentor $(\mathrm{mm})$

$\mathrm{d}=$ Diameter lekukan rata-rata hasil indentasi

Rumus untuk mencari beban yang sesuai yaitu :

$\mathrm{P}=\mathrm{C} \times D^{2}$

Dimana:

$\mathrm{P}=$ Beban yang diberikan

$\mathrm{C}=$ Konstanta bahan yang akan diuji ( untuk base ferro $=30$ )

$\mathrm{D}=$ Diameter indentor $(\mathrm{mm})$

Hasil perhitungan Uji kekerasan dapat dilihat pada Tabel 3 dan Gambar 3 di bawah ini : 
Tabel 3. Hasil Uji Kekersan

\begin{tabular}{cccccc}
\hline NO & $\begin{array}{c}\text { Hasil Uji Titik } \\
\text { I (BHN) }\end{array}$ & $\begin{array}{c}\text { Hasil Uji Titik } \\
\text { II (BHN) }\end{array}$ & $\begin{array}{c}\text { Hasil Uji Titik } \\
\text { III (BHN) }\end{array}$ & $\begin{array}{c}\text { Hasil Rata } \\
(\mathbf{B H N})\end{array}$ & (BHN) \\
\hline A1 & 128 & 144 & 146 & 139,3 & \\
A2 & 131 & 152 & 127 & 136,7 & 136,3 \\
A3 & 141 & 110 & 148 & 133 & \\
B1 & 219 & 196 & 247 & 220,7 & \\
B2 & 177 & 169 & 164 & 170 & 205,2 \\
B3 & 233 & 248 & 194 & 225 & \\
C1 & 174 & 192 & 181 & 182,3 & \\
C2 & 236 & 249 & 250 & 245 & 202,9 \\
C3 & 162 & 177 & 205 & 181,3 & \\
\hline
\end{tabular}

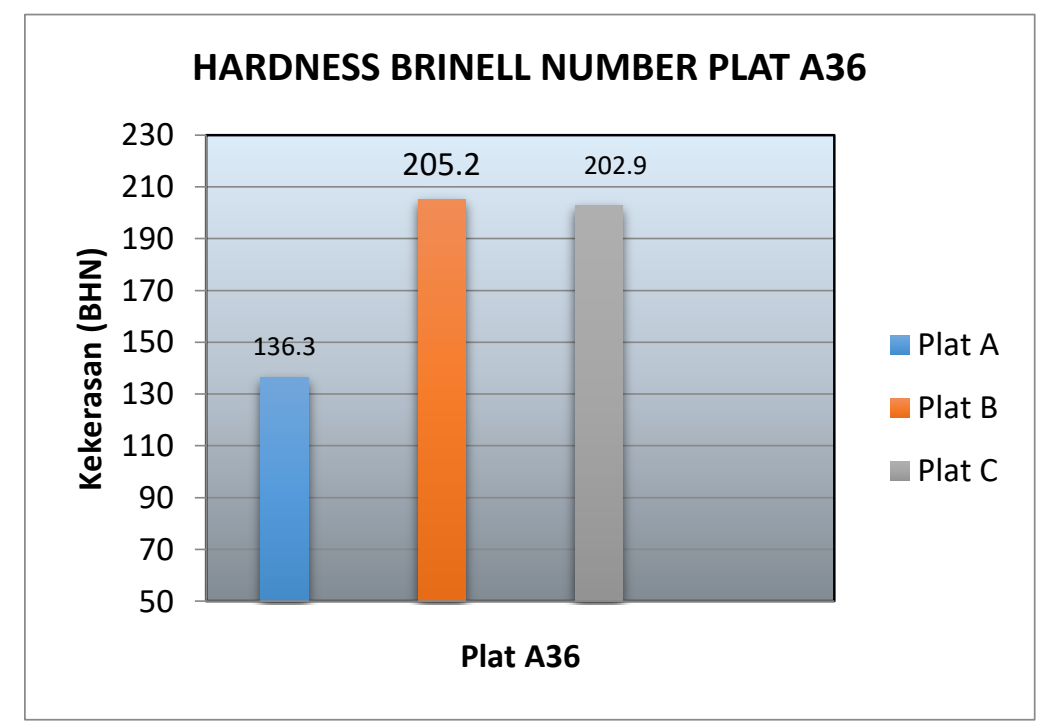

Gambar 3. Uji Kekerasan Plat A36 Pada Berbagai Perlakuan

\section{PEMBAHASAN}

Dari hasil perhitungan laju korosi pada ketiga sampel diperoleh hal-hal sebagai berikut :

1. Hasil percobaan laju korosi dengan plat tanpa menggunakan perlindungan menghasilkan laju korosi yang paling besar yaitu 0,66 mpy.

2. Dari perlindungan Korosi yang paling baik adalah dengan menggunakan perlindungan dengan zinc anode yang dialiri arus DC. Laju korosi pada plat ini sebesar 0,17 mpy (paling rendah)

3. Hasil pengujian kekerasan pada pengujian laju korosi tanpa perlindungan adalah 136,3 BHN, hasil pengujian kekerasan dengan perlindungan Zinc Anode adalah 205 BHN dan pada perlakuan gabungan antara Zinc Anode dan Arus DC yaitu 202.9 BHN, hasil ini berada diatas batas minimum kekerasan plat marine yaitu Proteksi katodik merupakan cara yang efektif dalam mencegah stress corrosion cracking (retak karena korosi), dengan cara mengembalikan arah arus korosi untuk mengembalikan elektron-elektron yang mengurai dari logam tertentu, yang bersifat kebal atau imun sehingga proses korosi pada logam dapat dikurangi atau ditiadakan (tidak sampai hilang).

Prinsip dari proteksi katodik (cathodic protection) adalah menyediakan elektron untuk struktur logam yang akan di lindungi. Teori yang mendasari adalah jika arus mengalir dari kutub positif ke kutub negatif (teori listrik konvensional) struktur akan terlindungi jika arus masuk dari elektrode. Kebalikannya laju korosi akan meningkat jika arus masuk melalui logam ke elektrode. Dalam proses korosi apabila terjadi goresan atau lapisan mengelupas, 
kedua logam akan muncul di permukaan. Adanya uap air, gas $\mathrm{CO} 2$ di udara dan partikelpartikel lain, terjadilah sel volta mini dengan Zn sebagai anodanya dan Fe sebagai katodanya. $\mathrm{Zn}$ akan teroksidasi terlebih dahulu karena harga $\mathrm{E}^{\mathrm{o}}$-nya lebih kecil daripada $\mathrm{Fe}$, sehingga korosi elektrolitik (reaksi elektrokimia yang mengoksidasi logam) tidak terjadi.

Dari hasil perhitungan laju korosi plat yang menggunakan perlindungan diperoleh hasil yang lebih baik dibandingkan dengan tanpa perlindungan. Hal ini terjadi karena perbedaan potensial, maka arus elektron akan mengalir dari anoda yang dipasang dan akan menahan melawan arus elektron dari logam yang di dekatnya, sehingga logam tersebut berubah menjadi daerah katoda. Inilah yang memperlambat plat mengalami laju korosi sedangkan sebaliknya plat tanpa perlindungan akan melepaskan elektron menyebabkan kerusakan plat sehingga mudah mengalami terjadinya korosi.

\section{KESIMPULAN}

Setelah melakukan eksperimen maka dapat mengambil kesimpulan yaitu :

1. Dari hasil ketiga percobaan diperoleh hasil yang menunjukkan bahwa terjadi korosi yang ditandai dengan berkurang nya berat benda.

2. Setelah dihitung nilai laju korosi dengan menggunakan rumus kehilangan berat pada bab IV, hasil nya adalah laju korosi lebih lambat apabila menggunakan perlindungan zinc anode dan arus DC, diikuti dengan perlindungan zinc anode dan yang terakhir tanpa menggunakan perlindungan.

3. Dari ketiga percobaan diperoleh bahwa nilai laju korosi dengan perlindungan dengan zinc anode dan arus DC adalah 0,17 mpy atau laju korosi adalah 17\%, kemudian dengan perlindungan zinc anode dengan nilai 0,22 mpy atau laju korosi adalah $22 \%$ dan yang terakhir adalah tanpa perlindungan nilai yang diperoleh adalah sebesar 0,66 mpy atau laju korosi adalah $66 \%$.

4. Dengan dilakukannya penelitian ini, sudah menjadi tahap awal untuk bisa diaplikasikan langsung, Sehingga penggunaan metode ini dapat menghemat biaya perbaikan rutin dalam industri perkapalan.

\section{DAFTAR PUSTAKA}

Afandi, Y. K., Arief, I. S., \& Amiadji, A. (2015). Analisa Laju Korosi Pada Pelat Baja Karbon Dengan Variasi Ketebalan Coating. Jurnal Teknik ITS, 4(1), G1-G5.

Bardal, E. (2007). Corrosion and protection. Springer Science \& Business Media.

Fontana, M. G. (2005). Corrosion engineering. Tata McGraw-Hill Education.

Riastuti, Rini dan Rustandi, Andi. 2008. Diktat Mata Kuliah Korosi dan Proteksi Logam. Depok.

Rumus Pengujian Keras Brinnel Vicker,http://kalogueloe.blogspot.com/2013/03/ Diakses Pada 18 April 2019

Susilowati, S. E., \& Sumardiyanto, D. (2018). Penerapan Marine Growth Prevention System (MGPS) Pada Pengoperasian Kapal Untuk Menghambat Laju Korosi. Jurnal Teknologi, 10(2), 95-102.

Trethewey, K. R., \& Chamberlain, J. (1995). Corrosion For Science And Engineering.

Utami, I. (2012). Proteksi Katodik Dengan Anoda Tumbal Sebagai Pengendalian Korosi Baja Dalam Lingkungan Aqueous. Jurnal Teknik Kimia, 3(2).

Van Vlack, L. H. (1983). Ilmu dan Teknologi Bahan (ilmu logam dan bukan logam). Penerbit Erlangga. 
Khairul Huda Huda, Edi Septe Septe, Iman Satria Satria (2015). Pengendalian Korosi Pada Plat Lambung Kapal Dengan Menggunakan Anoda Korban. bstrak dan Artikel Jurusan Teknik Industri. Vol : 7, No : 2

Didit Sumardiyanto, Sri Endah Susilowati. Effect of Welding Parameters on Mechanical Properties of Low Carbon Steel API 5L Shielded Metal Arc Welds. American Journal of Materials Science. Vol : 09, No : 01.2019 